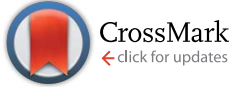

Cite this: RSC Adv., 2017, 7, 10183

Received 6th December 2016 Accepted 1st February 2017

DOI: $10.1039 / c 6 r a 27854 j$

rsc.li/rsc-advances

\section{The water-iodine oxide system: a revised mechanism for hydration and dehydration $\uparrow$}

\begin{abstract}
Dylan K. Smith, ${ }^{a}$ Michelle L. Pantoya, ${ }^{* a}$ Jeffrey S. Parkey ${ }^{\mathrm{b}}$ and Mehmet Kesmez $^{\mathrm{b}}$
lodic acids are widely studied in atmospheric and biological applications but their inherent hydrophilic properties introduce complexities that affect their functionality and reactivity. We have shown that iodic acid $\left(\mathrm{HIO}_{3}\right)$ dehydrates directly into iodine pentoxide $\left(\mathrm{I}_{2} \mathrm{O}_{5}\right)$ in contradiction to the generally accepted multi-step dehydration mechanism where $\mathrm{HIO}_{3}$ dehydrates into $\mathrm{HI}_{3} \mathrm{O}_{8}$ first, then dehydrates into $\mathrm{I}_{2} \mathrm{O}_{5}$. The generally accepted mechanism is used to determine the concentration of iodic acid by TGA and is only valid for special conditions. The revised mechanism allows for the determination of concentrations of iodic acids under all conditions, and the more specific conditions where the accepted mechanism is valid are shown. The determination of concentration of iodic acid with the revised dehydration mechanism is dependent on assumptions of residual water and initial concentration of $\mathrm{HI}_{3} \mathrm{O}_{8}$. The validity of these assumptions is established by studying the absorption and hydration behavior of $\mathrm{I}_{2} \mathrm{O}_{5}$ from atmospheric water. These results will have an impact on the handling and use of iodine.
\end{abstract}

\section{Introduction}

Iodine(v) oxides have biocidal potential in neutralizing bacterial agents released in certain weapon systems. Handling iodine(v) oxides is one of the biggest challenges toward their effective utilization in this application. Specifically, iodine(v) oxides are hygroscopic to the point of being deliquescent. A pile of diiodine pentoxide $\left(\mathrm{I}_{2} \mathrm{O}_{5}\right)$ powder, for example, will absorb so much water from the surrounding atmosphere over time, that a puddle is produced. This property has limited iodine(v) oxides usefulness in energetic applications because an abundance of water can greatly consume liberated energy from a chemical reaction between iodine(v) oxide and a metal fuel, such as aluminum, thereby inhibiting combustion performance. Understanding, absorption, hydration, desorption and dehydration mechanisms associated with iodine(v) oxides may enable more tailored synthesis and control over this property for engineering future prompt-agent-defeat technologies (or bio-agent defeat systems).

Iodine(v) oxide water absorption behavior is studied extensively with inconsistent results that may stem from a limited understanding of the fundamental kinetics and dynamics of water absorption and reaction with iodine(v) oxides. The inconsistencies highlighted here involve iodine(v) oxides reaction with water and include: different humidity levels where

\footnotetext{
${ }^{a}$ Department of Mechanical Engineering, Texas Tech University, Lubbock, TX 79409, USA. E-mail: michelle.pantoya@ttu.edu; Tel: +1-806-834-3733

${ }^{b}$ Lynntech, Inc., College Station, TX 77845, USA

$\dagger$ Electronic supplementary information (ESI) available. See DOI: $10.1039 /$ c6ra27854j
}

absorption begins; variations in concentration of iodic acids $\left(\mathrm{HIO}_{3}, \mathrm{HI}_{3} \mathrm{O}_{8}\right)$; crystal structure; onset temperature for dehydration and decomposition; and, absorption rates. All of the inconsistencies discussed below are affected by the hydration and dehydration mechanism.

The accepted mechanism for hydration of $\mathrm{I}_{2} \mathrm{O}_{5}$ into iodic acids (i.e., $\mathrm{HIO}_{3}$ and $\mathrm{HI}_{3} \mathrm{O}_{8}$ ) and dehydration of iodic acids into $\mathrm{I}_{2} \mathrm{O}_{5}$ (i.e., $\mathrm{HIO}_{3}$ and $\mathrm{HI}_{3} \mathrm{O}_{8}$ ) was first proposed by Selte et al. ${ }^{1}$ and shown in eqn (1a) and (1b), respectively. ${ }^{1}$

Hydration:

$$
3 \mathrm{I}_{2} \mathrm{O}_{5}+3 \mathrm{H}_{2} \mathrm{O} \rightarrow 2 \mathrm{HI}_{3} \mathrm{O}_{8}+2 \mathrm{H}_{2} \mathrm{O} \rightarrow 6 \mathrm{HIO}_{3}
$$

Dehydration:

$$
6 \mathrm{HIO}_{3} \rightarrow 2 \mathrm{HI}_{3} \mathrm{O}_{8}+2 \mathrm{H}_{2} \mathrm{O} \rightarrow 3 \mathrm{I}_{2} \mathrm{O}_{5}+3 \mathrm{H}_{2} \mathrm{O}
$$

In dehydration, six moles of iodic acid in the form of $\mathrm{HIO}_{3}$ form three moles of $\mathrm{I}_{2} \mathrm{O}_{5}$ and three moles of water with an intermediate step involving the formation of two moles of $\mathrm{HI}_{3} \mathrm{O}_{8}$. In this reaction, water comprises $5.11 \mathrm{wt} \%$ of the total mass. The mass loss from dehydration of water at each step is shown in eqn (2).

$$
\begin{aligned}
& 3 \mathrm{HIO}_{3} \rightarrow \mathrm{HI}_{3} \mathrm{O}_{8}+\mathrm{H}_{2} \mathrm{O}: 3.41 \% \text { water } \\
& 2 \mathrm{HI}_{3} \mathrm{O}_{8} \rightarrow 3 \mathrm{I}_{2} \mathrm{O}_{5}+\mathrm{H}_{2} \mathrm{O}: 1.76 \% \text { water }
\end{aligned}
$$

Using mass loss from water calculated from eqn (2a) and (2b), concentrations of iodic acids can be determined from thermal equilibrium analysis using differential scanning calorimetry (DSC) and thermal gravimetric analysis (TGA). ${ }^{1,2}$ The 
equations used to calculate concentration of $\mathrm{HIO}_{3}\left(X_{\mathrm{HIO}_{3}}\right)$ and $\mathrm{HI}_{3} \mathrm{O}_{8}\left(\mathrm{X}_{\mathrm{HI}_{3} \mathrm{O}_{8}}\right)$ are shown in eqn (3a) and (3b), respectively.

$$
\begin{aligned}
X_{\mathrm{HIO}_{3}} & =\frac{\mathrm{ML} \% \mathrm{HIO}_{3}}{3.46 \%} \\
X_{\mathrm{HI}_{3} \mathrm{O}_{8}} & =\frac{\mathrm{ML} \% \mathrm{HI}_{3} \mathrm{O}_{8}}{1.76 \%}
\end{aligned}
$$

In eqn (3), ML\% is measured mass loss from TGA. The mass loss percent is divided by the calculated maximum mass loss from eqn (2a) and (2b) for $\mathrm{HIO}_{3}$ and $\mathrm{HI}_{3} \mathrm{O}_{8}$ respectively, to obtain the concentration of each iodic acid. The DSC/TGA data shows an endotherm and mass loss at $110{ }^{\circ} \mathrm{C}$, where $\mathrm{HIO}_{3}$ dehydrates into $\mathrm{HI}_{3} \mathrm{O}_{8}$, followed by an endotherm and mass loss at $210{ }^{\circ} \mathrm{C}$, where $\mathrm{HI}_{3} \mathrm{O}_{8}$ dehydrates into $\mathrm{I}_{2} \mathrm{O}_{5}$. Dehydration of $\mathrm{HI}_{3} \mathrm{O}_{8}$ has always been observed when $\mathrm{HIO}_{3}$ dehydration was observed, indicating an intermediate step where $\mathrm{HIO}_{3}$ dehydrates into $\mathrm{HI}_{3} \mathrm{O}_{8}{ }^{1,2}$ In Selte et al. ${ }^{1}$ and multiple references within, determination of iodic acid concentration by TGA is confirmed with XRD analysis. The temperatures where the onset of iodic acid dehydration begins is widely varied and often overlooked.

A review of the publications over the thermochemical properties of iodine oxides ${ }^{3}$ summarized data available for reported onset temperatures of each dehydration step and decomposition of $\mathrm{I}_{2} \mathrm{O}_{5}$. The onset temperatures reported for $\mathrm{I}_{2} \mathrm{O}_{5}$ decomposition are between 300 and $450{ }^{\circ} \mathrm{C} .{ }^{3}$ Selte et al. report a lower onset temperature of $280{ }^{\circ} \mathrm{C}$ for amorphous $\mathrm{I}_{2} \mathrm{O}_{5}$, with onset temperatures between 300 and $420^{\circ} \mathrm{C}$ for crystalline $\mathrm{I}_{2} \mathrm{O}_{5} .{ }^{1}$ Iodic acids such as $\mathrm{HI}_{3} \mathrm{O}_{8}$ onset temperatures are reported between 195 and $220{ }^{\circ} \mathrm{C}$ (ref. 1) and between 100 and $130{ }^{\circ} \mathrm{C}$ for $\mathrm{HIO}_{3}{ }^{1}$ The reason for the variation in temperature is not known. Formation of hydrated species of iodine oxides is a complex, dynamic process that can depend on variables such as relative humidity (RH), particle size, hydration and desorption rates, available water, and crystal structure. These variables can be dependent on each other and could affect properties of the final material including dehydration temperature.

Relative humidity (RH) has a significant influence on the oxidation state and kinetics of iodine(v) oxides. Selte et al. ${ }^{1}$ report that crystalline $\mathrm{HI}_{3} \mathrm{O}_{8}$ powder can be stored in open vessels for an indefinite period independent of atmospheric humidity but fine-powdered samples completely convert to $\mathrm{HIO}_{3}$ in moist air. Kumar et al. ${ }^{4}$ studied the deliquescence and efflorescence behavior of $\mathrm{I}_{2} \mathrm{O}_{5}$ and $\mathrm{HIO}_{3}$. They describe deliquescence as the transformation from a solid crystal phase to an aqueous solution and efflorescence as the reverse, when an aqueous solution crystallizes to a solid phase; and, define these differences by changes in the optical properties of the sample. Deliquescence and efflorescence are seen at specific threshold RH levels. Also, $\mathrm{I}_{2} \mathrm{O}_{5}$ and $\mathrm{HIO}_{3}$ crystals with an average size of 10-50 $\mu \mathrm{m}$ were studied at different temperatures. Deliquescence was reported at $85 \% \mathrm{RH}$ and room temperature for $\mathrm{HIO}_{3}$, and at $80 \% \mathrm{RH}$ and room temperature for $\mathrm{I}_{2} \mathrm{O}_{5} \cdot{ }^{4}$ Efflorescence was not seen in iodine(v) oxide samples with $\mathrm{RH}$ as low as $1.0 \%$. Little et $a .^{2}$ observed hydration according to the steps in the hydration mechanism in eqn (1a). They explain different hydrated species of iodine(v) oxide can precipitate out when exposed to water and recrystallize depending on impurities, rate of evaporation, and crystal structure. ${ }^{2}$ This finding is in contrast to Selte et al., ${ }^{1}$ where all samples were exclusively $\mathrm{HIO}_{3}$. Little et al. ${ }^{2}$ note that multiple iterations of this method produced varying concentrations of iodic acid. Also, a threshold value of $60 \% \mathrm{RH}$ was found by Little et al. ${ }^{2}$ to hydrate commercially available samples without dissolving the solid in water and recrystallization. When commercially available samples are exposed to air above $60 \% \mathrm{RH}$ threshold, the product is $\mathrm{HIO}_{3}$ and when exposed to air below $60 \% \mathrm{RH}$, no hydration is observed. Because the commercial sample was entirely $\mathrm{HI}_{3} \mathrm{O}_{8}$, a threshold of $60 \% \mathrm{RH}$ was assumed to be the $\mathrm{RH}$ that $\mathrm{HI}_{3} \mathrm{O}_{8}$ started absorbing water. ${ }^{2}$ To obtain $\mathrm{I}_{2} \mathrm{O}_{5}$, a sample initially $\mathrm{HI}_{3} \mathrm{O}_{8}$ was ball milled, and produced a sample $75 \mathrm{wt} \% \mathrm{I}_{2} \mathrm{O}_{5}$ and $25 \mathrm{wt} \%$ $\mathrm{HI}_{3} \mathrm{O}_{8}$. For hydration from $\mathrm{I}_{2} \mathrm{O}_{5}$ to $\mathrm{HI}_{3} \mathrm{O}_{8}$, Little et al. ${ }^{2}$ exposed the ball milled samples to $40 \%$ RH over a period of several days. The TG analysis indicated increased mass loss at $210{ }^{\circ} \mathrm{C}$ such that samples with higher concentrations of $\mathrm{I}_{2} \mathrm{O}_{5}$ were hydrated at $40 \% \mathrm{RH}$. It is interesting to note that the observation of an endotherm with an onset temperature of $170{ }^{\circ} \mathrm{C}$ remained constant with increased hydration. An endotherm with an onset temperature of $170{ }^{\circ} \mathrm{C}$ is outside of the range of generally accepted dehydration temperatures for hydrated species of iodine oxides. Over time with exposure to $40 \% \mathrm{RH}$, the endothermic peak indicating $\mathrm{HI}_{3} \mathrm{O}_{8}$ increased and formed a double peak. Commercially available $\mathrm{I}_{2} \mathrm{O}_{5}$ was used to study the hydration step from $\mathrm{HI}_{3} \mathrm{O}_{8}$ to $\mathrm{HIO}_{3}$ (eqn (1a)). No hydration was seen below $50 \% \mathrm{RH}$ over a period of weeks, however, hydration was seen when $\mathrm{RH}$ increased to $70 \% \mathrm{RH}$. Hydration rates were measured at $70 \% \mathrm{RH}$ for $\mathrm{HI}_{3} \mathrm{O}_{8}$ to $\mathrm{HIO}_{3}$ (eqn (1a)) and at $40 \%$ RH for $\mathrm{I}_{2} \mathrm{O}_{5}$ to $\mathrm{HI}_{3} \mathrm{O}_{8}$ (eqn (1a)). At $40 \% \mathrm{RH}$, the hydration rate went to 0 before $80 \mathrm{wt} \%$ of the sample was $\mathrm{HI}_{3} \mathrm{O}_{8}$, but at $70 \% \mathrm{RH}$ hydration continued until the sample was solely $\mathrm{HIO}_{3}$. In summary, a discrepancy from previous research is that water absorption thresholds for any iodic acid widely range from 0 to $85 \% \mathrm{RH}$. The reason for the dramatic variation may be due to limited understanding of the fundamental mechanism of hydration and dehydration. A better understanding of the fundamental hydration and dehydration kinetics is needed to reconcile these discrepancies.

Our goal is to improve the fundamental mechanism of hydration and dehydration of $\mathrm{I}_{2} \mathrm{O}_{5}$ by studying hydration and dehydration from atmospheric water (i.e. relative humidity). The objectives are to understand the fundamental absorption mechanism of $\mathrm{I}_{2} \mathrm{O}_{5}$; understand how $\mathrm{I}_{2} \mathrm{O}_{5}$ reacts with water to form iodic acids; and, identify how the reactions between $\mathrm{I}_{2} \mathrm{O}_{5}$ and water affect the kinetics of hydration and dehydration. It is noted that hydration and absorption are not interchangeable terms. For the purpose of this study, absorption refers to water that is weakly bonded and not yet reacted to hydrate $\mathrm{I}_{2} \mathrm{O}_{5}$ into $\mathrm{HIO}_{3}$. Hydration refers to absorbed water that has reacted to form an $\mathrm{IO}_{3}{ }^{-}$solution and will form an $\mathrm{HIO}_{3}$ crystal structure upon desorption. Desorption is when mass loss occurs without heating and dehydration is mass loss as a result of $\mathrm{HIO}_{3}$ forming $\mathrm{I}_{2} \mathrm{O}_{5}$ from heating. 


\section{Experimental}

$\mathbf{I}_{2} \mathbf{O}_{5}$

Two synthesis procedures are used to produce $\mathrm{I}_{2} \mathrm{O}_{5}$ powders. One method is based on the thermal dehydration of iodic acid to form $\mathrm{I}_{2} \mathrm{O}_{5} \cdot{ }^{5,6}$ These samples were supplied by Sigma Aldrich (St. Louis, MO) and come as crystals that require the sample to be crushed using a mortar and pestle. This sample is referred to as $17 \mu \mathrm{m} \mathrm{I}_{2} \mathrm{O}_{5}$ because it has an average particle diameter of 16.9 $\mu \mathrm{m} .^{7}$ The $17 \mu \mathrm{m} \mathrm{I}_{2} \mathrm{O}_{5}$ is the same as commercial $\mathrm{I}_{2} \mathrm{O}_{5}$ used in Smith et al. ${ }^{7}$ where characterization of these samples was performed. The second method is a "dry" method that combines elemental iodine and oxygen using a non-thermal plasma energy source to form spherical $\mathrm{I}_{2} \mathrm{O}_{5}$ particles with an average diameter of $4.7 \mu \mathrm{m} .^{7}$ These samples were labeled nano $\mathrm{C}_{2} \mathrm{O}_{5}$ when used in Smith et al. ${ }^{7}$ because they were initially measured erroneously to have an average particle diameter of $400 \mathrm{~nm} .^{7}$ This sample is now referred to as $5 \mu \mathrm{m} \mathrm{I}_{2} \mathrm{O}_{5}$ here. The two distinct synthesis methods enable production of particles with discretely different properties inherent from the synthesis methods and tailored for experimental designs that focus on deriving a more general hydration/dehydration mechanism.

\section{Humidity chamber}

A humidity chamber was designed and built to control relative humidity, RH. The chamber was designed from a $60 \times 30 \times$ $30 \mathrm{~cm}$ acrylic air tight box. A $1.27 \mathrm{~cm}$ hole was drilled in the wall of the chamber and a variable speed fan was placed outside the chamber so the current of air from the fan passed over a hole to draw air out of the inside the chamber. A heating pad was placed inside the chamber and a Pyrex ${ }^{\mathrm{TM}}$ pan filled with water positioned on top of the heating pad. Humidity was controlled by adjusting the temperature on the heating pad and the speed of the air from the fan. Relative humidity was measured with an AMPROBE TH-3 relative humidity temperature meter and was held above $80 \%$ but below the dew point at a temperature of $23{ }^{\circ} \mathrm{C}$ so drops of water did not condense inside the chamber. The $80 \% \mathrm{RH}$ threshold was selected because it is the highest $\mathrm{RH}$ without having droplets form and thus a reasonable upper bound for this study.

\section{Thermal equilibrium analysis}

Simultaneous thermal analysis (STA) was performed using a Netzsch model STA 449 differential scanning calorimeter (DSC) with thermo-gravimetric (TG) analyzer. All powder samples measured approximately $10 \mathrm{mg}$ and were placed inside alumina crucibles designed for the STA 449 DSC-TGA. To ensure the samples were initially comprised of only $\mathrm{I}_{2} \mathrm{O}_{5}$ and not another form of iodic acid, all samples were heated in a Neytech QEX oven to $250{ }^{\circ} \mathrm{C}$, above the dehydration temperature of $\mathrm{HIO}_{3}$ $\left(110{ }^{\circ} \mathrm{C}\right)$ and $\mathrm{HI}_{3} \mathrm{O}_{8}\left(210{ }^{\circ} \mathrm{C}\right)$ but below the dissociation temperature of $\mathrm{I}_{2} \mathrm{O}_{5}\left(350{ }^{\circ} \mathrm{C}\right)$, and held for 5 minutes. The heat flow and mass loss showing that samples are pure $\mathrm{I}_{2} \mathrm{O}_{5}$ after heat treatment are shown in ESI Fig. S1. $\dagger$ The sample covers were removed and the samples were placed inside the humidity controlled chamber for varying intervals. The samples were

Table 1 Mass gain from absorption and hydration at $80 \% \mathrm{RH}\left(23^{\circ} \mathrm{C}\right)$ and mass loss from TG analysis for $17 \mu \mathrm{m} \mathrm{I}_{2} \mathrm{O}_{5}$. Mass gain is measured by weighing samples before and after exposure to $80 \% \mathrm{RH}$ and shows absorption. Mass loss is obtained by TG measurements in the iodic acid dehydration temperature range and indicates hydration. The ratio $\mathrm{HIO}_{3} / \mathrm{HI}_{3} \mathrm{O}_{8}$ indicates percent mass loss by $\mathrm{HIO}_{3}$ to percent mass loss by $\mathrm{HI}{ }_{3} \mathrm{O}_{8}$

\begin{tabular}{|c|c|c|c|c|c|}
\hline Exposure time (min) & Mass gain, $\%$ & $\mathrm{HIO}_{3}$ mass loss, \% & $\mathrm{HI}_{3} \mathrm{O}_{8}$ mass loss, $\%$ & Total mass loss & $\mathrm{HIO}_{3} / \mathrm{HI}_{3} \mathrm{O}_{8}$ \\
\hline 1 & $1.0 \%$ & $0.0 \%$ & $0.02 \%$ & $0.02 \%$ & 0.00 \\
\hline 5 & $1.5 \%$ & $0.0 \%$ & $0.08 \%$ & $0.08 \%$ & 0.00 \\
\hline 10 & $3.2 \%$ & $0.0 \%$ & $0.06 \%$ & $0.06 \%$ & 0.00 \\
\hline 15 & $9.0 \%$ & $1.63 \%$ & $0.23 \%$ & $1.86 \%$ & 7.09 \\
\hline 30 & $13.7 \%$ & $2.70 \%$ & $0.10 \%$ & $2.80 \%$ & 27.00 \\
\hline 180 & $34.8 \%$ & $5.36 \%$ & $0.22 \%$ & $5.58 \%$ & 24.36 \\
\hline 900 & $32.7 \%$ & $7.41 \%$ & $0.17 \%$ & $7.58 \%$ & 43.59 \\
\hline 2680 & $23.1 \%$ & $8.49 \%$ & $0.29 \%$ & $8.78 \%$ & 29.28 \\
\hline
\end{tabular}

Table 2 Mass gain from absorption and hydration at $80 \% \mathrm{RH}\left(23^{\circ} \mathrm{C}\right)$ and mass loss from TG analysis for $5 \mu \mathrm{m} \mathrm{I} \mathrm{O}_{5}$. Mass gain is by weighing samples before and after exposure to $80 \% \mathrm{RH}$ and shows absorption. Mass loss is obtained by TG measurements in the iodic acid dehydration temperature range and indicates hydration. The ratio $\mathrm{HIO}_{3} / \mathrm{HI}_{3} \mathrm{O}_{8}$ indicates percent mass loss by $\mathrm{HIO}_{3}$ to percent mass loss by $\mathrm{HI}_{3} \mathrm{O}_{8}$

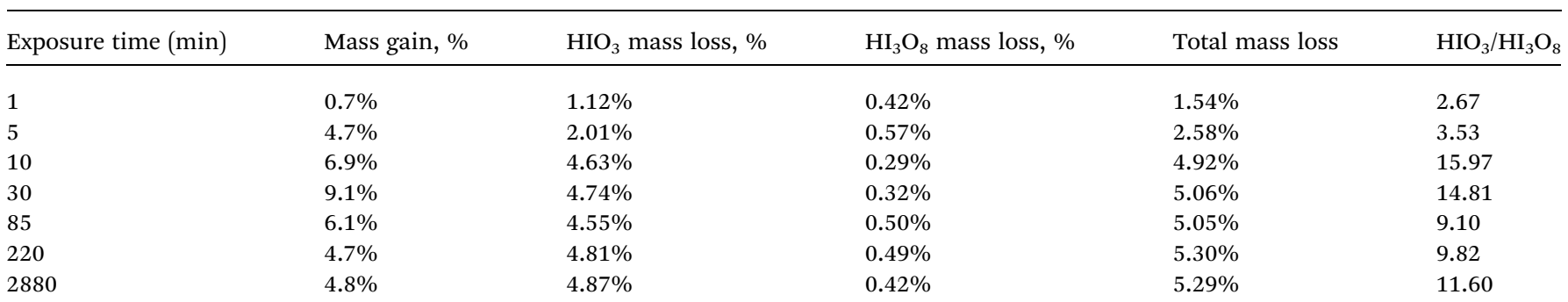


weighed before and after they were placed inside the humidity controlled chamber and the mass change is reported as a percentage in Tables 1 and 2 . It is important to note that the starting material was purposefully heated such that the material is initially solely $\mathrm{I}_{2} \mathrm{O}_{5}$ as shown in Fig. S1. $\dagger$ Most other studies reporting iodine(v) compounds may not start with pure $\mathrm{I}_{2} \mathrm{O}_{5}$ as the precursor because a heat treatment procedure as described above is not mentioned., ${ }^{2,4,8}$ Each sample was covered and loaded into the STA manually to minimize exposure time to the ambient held at an average $20 \% \mathrm{RH}$. Samples were heated to $600{ }^{\circ} \mathrm{C}$ at $10{ }^{\circ} \mathrm{C} \min ^{-1}$ in an argon atmosphere. The argon atmosphere was created by a constant flow of argon into the STA at $100 \mathrm{ml} \mathrm{min} \mathrm{m}^{-1}$. The control software for the STA requires a 1 min equilibration period between sample loading and heating that ensures the atmosphere inside the STA is argon. This equilibration period is included in the time interval between when the samples were removed from $80 \% \mathrm{RH}$ and measurements.

\section{Results}

Fig. $1 \mathrm{a}$ and $\mathrm{b}$ are the heat flow from DSC and mass change from TG measurements as a function of exposure time to $80 \% \mathrm{RH}$ from 1 to 3060 minutes for $17 \mu \mathrm{m} \mathrm{I}_{2} \mathrm{O}_{5}$, respectively. Fig. 1a shows
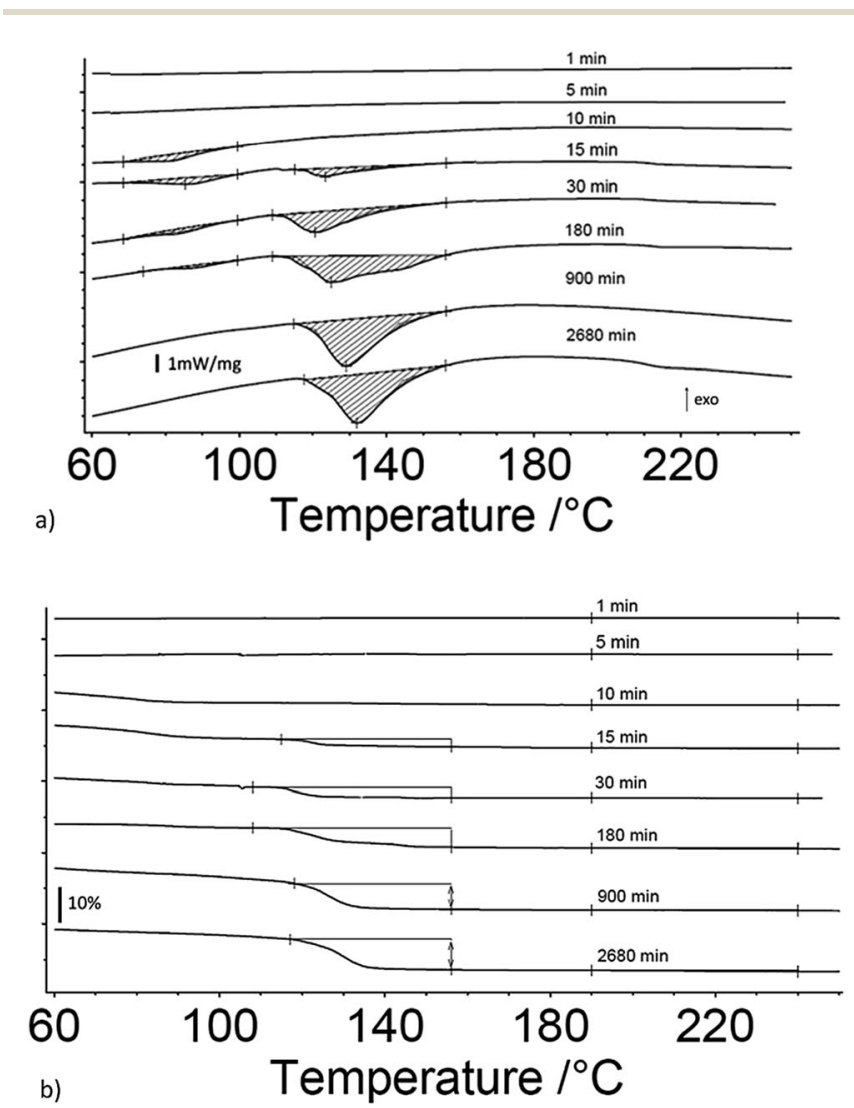

Fig. 1 (a) DSC measurements of heat flow for $17 \mu \mathrm{m} \mathrm{I}_{2} \mathrm{O}_{5}$ at different exposure time intervals to $80 \% \mathrm{RH}$ as indicated on the curves; and, (b) TG measurements of mass change for $17 \mu \mathrm{m} \mathrm{I}_{2} \mathrm{O}_{5}$ at different exposure time intervals to $80 \% \mathrm{RH}$ as indicated on the curves. Onset and end temperature for measurements of mass loss are determined by endotherm onset and end temperatures. endothermic reactions starting at an exposure time of 10 minutes. At an exposure time of 15 minutes, there are two distinct endotherms below $160{ }^{\circ} \mathrm{C}$. The second endotherm, with onset at $110{ }^{\circ} \mathrm{C}$, increases in magnitude with time while the first endotherm reduces in magnitude until 900 minutes exposure time where it is no longer detectable. To the authors' knowledge, two distinct peaks in the range of $\mathrm{HIO}_{3}$ dehydration have not been reported previously. However, similar endothermic activity reported in Smith et al. ${ }^{10}$ observed a single endotherm with a double peak before $110{ }^{\circ} \mathrm{C}$. They proposed the multiple endothermic activity in this temperature range was latent water or $\mathrm{IO}_{3}{ }^{-}$solution formed when iodine oxides react with water, and that theory is supported by the results shown here. The first endotherm in samples that show two endotherms is assumed to be evaporation of latent water and only mass loss from the second endotherm is used for calculation of mass loss from dehydration of $\mathrm{HIO}_{3}$. Additionally, most samples showed slight endothermic activity at $210^{\circ} \mathrm{C}$ with corresponding mass loss (Fig. 1b). The beginning and ending points for mass loss in Fig. 1b are taken from endotherm onset and ending temperatures in Fig. 1a. All mass loss for $\mathrm{HIO}_{3}$ and $\mathrm{HI}_{3} \mathrm{O}_{8}$ dehydration corresponding to the endotherms in Fig. 1a are shown in Fig. $1 \mathrm{~b}$ and tabulated along with the mass increase from absorption and mass loss from hydration when exposed to $80 \% \mathrm{RH}$ in Table 1.
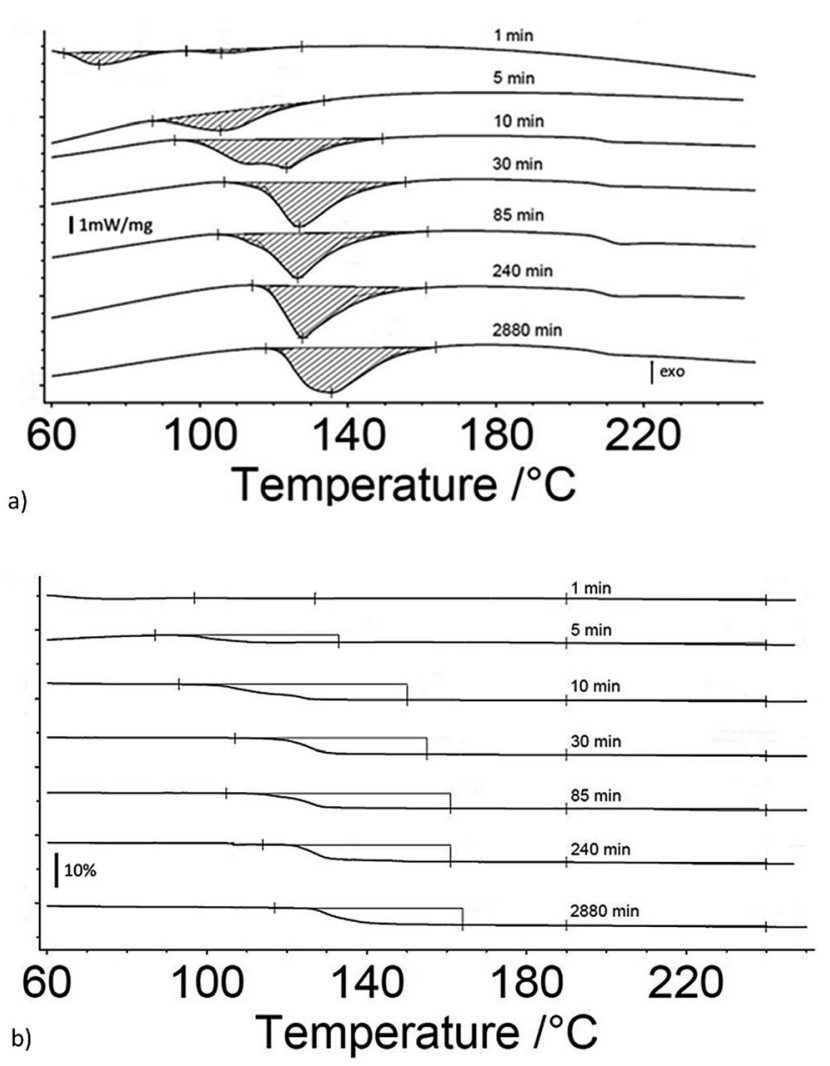

Fig. 2 (a) DSC measurements of heat flow for $5 \mu \mathrm{m} \mathrm{I}_{2} \mathrm{O}_{5}$ at different exposure time intervals to $80 \% \mathrm{RH}$ as indicated on the curves; and, (b) $\mathrm{TG}$ measurements of mass change for $5 \mu \mathrm{m} \mathrm{I}_{2} \mathrm{O}_{5}$ after different exposure time intervals to $80 \% \mathrm{RH}$ as indicated on the curves. Onset and end temperature for measurements of mass loss are determined by endotherm onset and end temperatures. 
Fig. 2a and $\mathrm{b}$ are the heat flow from DSC and mass change from TG measurements as a function of exposure time to $80 \%$ $\mathrm{RH}$ from 1 to 2880 minutes for $5 \mu \mathrm{m} \mathrm{I}_{2} \mathrm{O}_{5}$. Fig. 2a shows two distinct endotherms with onset temperature below $110^{\circ} \mathrm{C}$ at an exposure time of 1 minute. With an exposure time of 5 minutes, there is only one distinct endotherm with an onset temperature of $90{ }^{\circ} \mathrm{C}$. These endotherms increase in magnitude and onset temperature through the entire range tested. Fig. 2a shows most $5 \mu \mathrm{m} \mathrm{I}_{2} \mathrm{O}_{5}$ samples produce an endotherm at $210{ }^{\circ} \mathrm{C}$ with an associated mass loss (Fig. 2b). The beginning and ending temperatures for mass loss in Fig. $2 \mathrm{~b}$ are taken from endotherm onset and end temperatures in Fig. 2a. Table 2 summarizes the data in Fig. $2 b$ along with the mass increase from absorption.
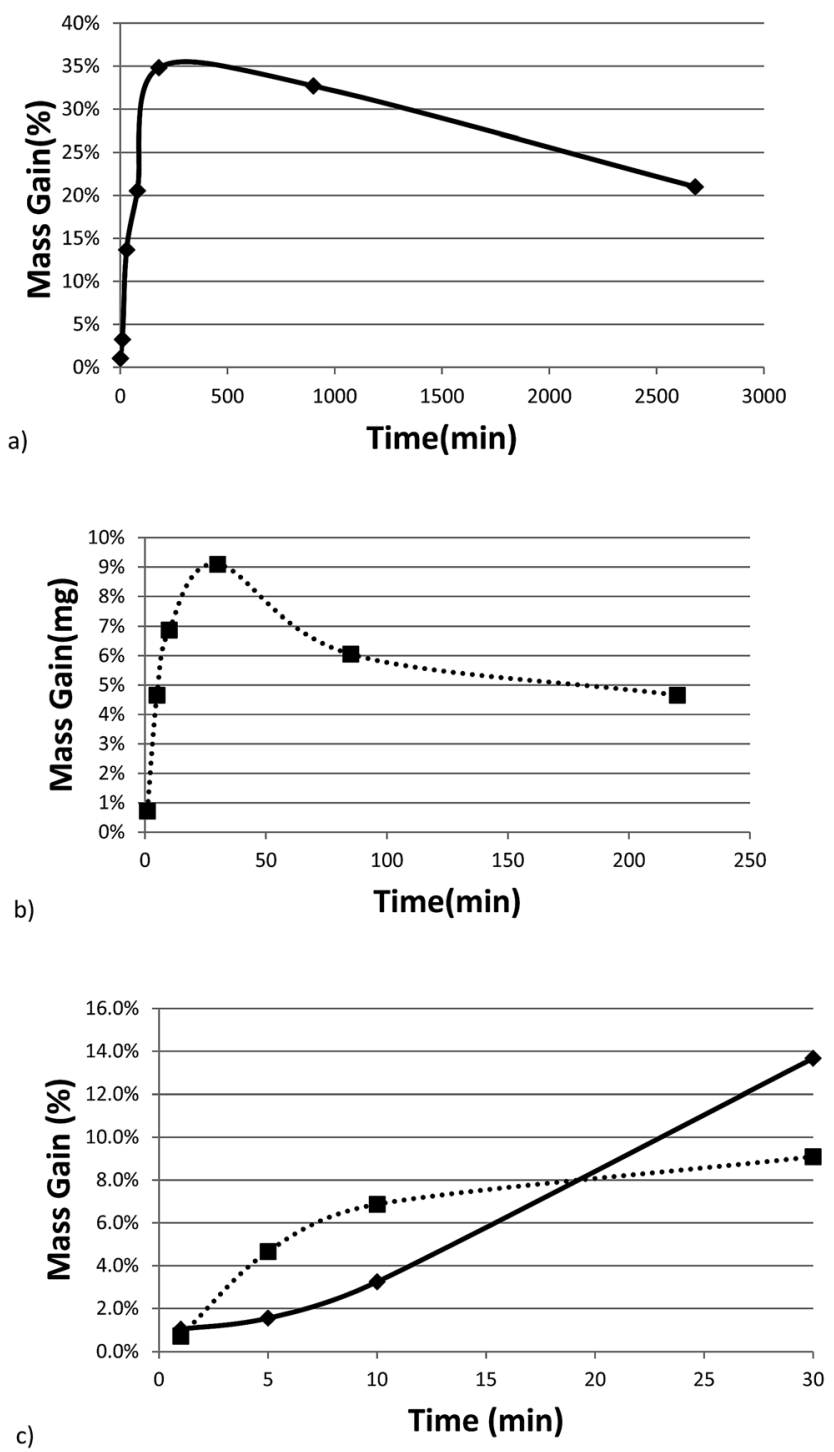

Fig. 3 All graphs provide information on the relative rates of absorption, hydration or dehydration as a function of particle size. Samples shown are exposed to $80 \% \mathrm{RH}\left(23^{\circ} \mathrm{C}\right)$ throughout the entire duration. (a) Mass gain percentage as a function of time for $17 \mu \mathrm{m} \mathrm{I}_{2} \mathrm{O}_{5}$. (b) Mass gain percentage as a function of time for $5 \mu \mathrm{m} \mathrm{I}_{2} \mathrm{O}_{5}$ up to 220 minutes (i.e., 2880 minute data excluded from graph for clarity of presentation but all data shown in Table 2 and Fig S2 $†$ ). (c) Mass gain for both $5 \mu \mathrm{m} \mathrm{I}_{2} \mathrm{O}_{5}$ (dashed line) and 17 $\mu \mathrm{m} \mathrm{I}_{2} \mathrm{O}_{5}$ (solid line) for the first 30 minutes of exposure to $80 \% \mathrm{RH}$.
Fig. 3a and b show the mass gain for $17 \mu \mathrm{m} \mathrm{I}_{2} \mathrm{O}_{5}$ and $5 \mu \mathrm{m}$ $\mathrm{I}_{2} \mathrm{O}_{5}$ respectively, determined by weighing the samples before and after exposure to $80 \% \mathrm{RH}$ at $23{ }^{\circ} \mathrm{C}$ for the indicated exposure times. The mass gain for $17 \mu \mathrm{m} \mathrm{I}_{2} \mathrm{O}_{5}$ increases to a maximum of $34.8 \%$ at an exposure time of 180 minutes and then decreases to $7.0 \%$ at an exposure time of 3060 minutes. The mass gain for $5 \mu \mathrm{m} \mathrm{I}_{2} \mathrm{O}_{5}$ increases to a maximum of $9.1 \%$ at an exposure time of 30 minutes then decreases to $4.8 \%$ at an exposure time of 2880 minutes. An opposite trend is seen in the mass gain rate in Fig. $3 \mathrm{a}$ and $\mathrm{b}$ after the mass gain rate starts to decrease, the decrease in the $5 \mu \mathrm{m} \mathrm{I}_{2} \mathrm{O}_{5}$ mass gain after an exposure time of $30 \mathrm{~min}$ is initially fast and slows with increased exposure time, while $17 \mu \mathrm{m} \mathrm{I}_{2} \mathrm{O}_{5}$ is initially slow and increases with exposure time.

Fig. 3c shows the mass gain for both $5 \mu \mathrm{m} \mathrm{I} \mathrm{I}_{2} \mathrm{O}_{5}$ and $17 \mu \mathrm{m}$ $\mathrm{I}_{2} \mathrm{O}_{5}$ for exposure time periods less than 30 minutes. The mass gain rate for the $5 \mu \mathrm{m} \mathrm{I}_{2} \mathrm{O}_{5}$ is linear until an exposure time of 5 minutes, then starts plateauing at an exposure time of 5 minutes. In contrast, the mass gain for $17 \mu \mathrm{m} \mathrm{I}_{2} \mathrm{O}_{5}$ is negligible until an exposure time of 5 minutes, then starts to increase.

\section{Discussion}

\section{Mechanism}

The mechanism in eqn (1a) and (1b) assumes that one mole of water and two moles of $\mathrm{I}_{2} \mathrm{O}_{5}$ initially react to form $\mathrm{HI}_{3} \mathrm{O}_{8}$, and then two moles of water and two moles of $\mathrm{HI}_{3} \mathrm{O}_{8}$ react to form $\mathrm{HIO}_{3}$. This intermediate step (i.e., formation of $\mathrm{HI}_{3} \mathrm{O}_{8}$ before $\mathrm{HIO}_{3}$ ) in the formation of $\mathrm{HIO}_{3}$ from $\mathrm{I}_{2} \mathrm{O}_{5}$ is assumed because in almost all reported cases, there is an endothermic peak at $210{ }^{\circ} \mathrm{C}$, the dehydration temperature of $\mathrm{HI}_{3} \mathrm{O}_{8}$, and an associated mass loss that corresponds to the mechanism in eqn (1a) and (1b). ${ }^{1,2}$ Eqn (1) and TG mass loss (Tables 1 and 2 along with Fig. $1 \mathrm{~b}$ and $2 \mathrm{~b}$ ) can be used to calculate the initial concentration of $\mathrm{HIO}_{3}$. Eqn (2a) and (2b) show the dehydration steps of both iodic acids along with the mass percent of water in each step. If the mechanism accepted and described in eqn (1a) and (1b) is correct, the mass loss in the $\mathrm{HIO}_{3}$ dehydration temperature range cannot be greater than $3.41 \%$ if there is no residual water. Mass loss from $\mathrm{HIO}_{3}$ greater than $3.41 \%$ will give a concentration of $\mathrm{HIO}_{3}$ greater than $100 \%$ when calculated using eqn (3a).

The mechanism in eqn (1) also has a condition that $\mathrm{HIO}_{3}$ dehydrates directly into $\mathrm{HI}_{3} \mathrm{O}_{8}$. This condition is represented by the ratio of mass loss of $\mathrm{HIO}_{3}$ to $\mathrm{HI}_{3} \mathrm{O}_{8}$. The maximum ratio of mass loss percentage at $110{ }^{\circ} \mathrm{C}$ for $\mathrm{HIO}_{3}$ to mass loss percentage at $210{ }^{\circ} \mathrm{C}$ for $\mathrm{HI}_{3} \mathrm{O}_{8}$ should be 3.41 : 1.76 (i.e., a ratio of 1.94). A ratio higher than 1.94 indicates that a portion of $\mathrm{HIO}_{3}$ is dehydrating directly into $\mathrm{I}_{2} \mathrm{O}_{5}$ (not $\mathrm{HI}_{3} \mathrm{O}_{8}$ ) and is seen for multiple samples (highlighted in Tables 1 and 2). These results indicate a new mechanism is needed and presented in eqn (4a) and (4b) for hydration and dehydration of $\mathrm{I}_{2} \mathrm{O}_{5}$ that does not have an intermediate step resulting in the formation of $\mathrm{HI}_{3} \mathrm{O}_{8}$.

Hydration:

$$
\mathrm{I}_{2} \mathrm{O}_{5}+\mathrm{H}_{2} \mathrm{O} \rightarrow 2 \mathrm{HIO}_{3}
$$

Dehydration: 


$$
2 \mathrm{HIO}_{3} \rightarrow \mathrm{I}_{2} \mathrm{O}_{5}+\mathrm{H}_{2} \mathrm{O}
$$

The mechanism in eqn (4a) and (4b) is proposed because the accepted mechanism (eqn (1)) is valid only under the condition that all $\mathrm{HIO}_{3}$ forms $\mathrm{HI}_{3} \mathrm{O}_{8}$ (eqn (2a)) during heating. The initial concentrations of $\mathrm{HIO}_{3}$ and $\mathrm{I}_{2} \mathrm{O}_{5}$ can be calculated from TG analysis of mass loss as tabulated in Tables 1 and 2 and eqn (4). The equations to calculate initial concentration of $\mathrm{HIO}_{3}$ and $\mathrm{I}_{2} \mathrm{O}_{5}$ from eqn (4) are shown in eqn (5a) and (5b).

$$
\begin{gathered}
X_{\mathrm{HIO}_{3}}=\frac{\mathrm{ML} \% \text { total }}{5.11 \%}-X_{\mathrm{HI}_{3} \mathrm{O}_{8}, \text { initial }} \\
X_{\mathrm{I}_{2} \mathrm{O}_{5}}=1-X_{\mathrm{HIO}_{3}}
\end{gathered}
$$

In eqn (5), $X$ is the concentration of $\mathrm{HIO}_{3}$ or $\mathrm{I}_{2} \mathrm{O}_{5}$ as indicated, $\mathrm{ML} \%_{\text {total }}$ is the measured mass loss for the entire iodic

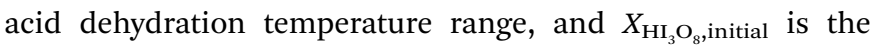
initial concentration of $\mathrm{HI}_{3} \mathrm{O}_{8}$. The total measured mass loss is divided by the calculated mass loss percent of total water (5.11\%), not including residual water, calculated from eqn (4b).

Eqn (1)-(3) represent a model for the previously accepted hydration/dehydration mechanism that enables determination of the concentration of iodine species by TGA mass change measurements. A new model is presented in eqn (4)-(7). The major difference between the models shown is seen by comparing eqn (5) to (3) and is that $\mathrm{HIO}_{3}$ dehydrates into $\mathrm{I}_{2} \mathrm{O}_{5}$ instead of $\mathrm{HI}_{3} \mathrm{O}_{8}$, and that $\mathrm{HI}_{3} \mathrm{O}_{8}$ is formed during heating. The amount of $\mathrm{HI}_{3} \mathrm{O}_{8}$ that is formed during heating is accounted for by using the total mass loss in the iodic acid $\left(\mathrm{HIO}_{3}\right.$ and $\left.\mathrm{HI}_{3} \mathrm{O}_{8}\right)$ dehydration temperature range instead of the individual mass loss from $\mathrm{HIO}_{3}$ and $\mathrm{HI}_{3} \mathrm{O}_{8}$ dehydration respectively (e.g., used in eqn (3a) and (3b)). The model in eqn (5) includes a term for initial concentration of $\mathrm{HI}_{3} \mathrm{O}_{8}$. The DSC cannot differentiate between initial $\mathrm{HI}_{3} \mathrm{O}_{8}$ and $\mathrm{HI}_{3} \mathrm{O}_{8}$ that is formed during heating. To accurately determine the concentration of $\mathrm{HIO}_{3}$ and $\mathrm{I}_{2} \mathrm{O}_{5}$ using eqn (5), the initial concentration of $\mathrm{HI}_{3} \mathrm{O}_{8}$ is needed. In this study, the initial concentration of $\mathrm{HI}_{3} \mathrm{O}_{8}$ is assumed to be $0.0 \%$ because the samples are initially dehydrated before hydration in $80 \% \mathrm{RH}$. The validity of this assumption is discussed below. The amount of $\mathrm{HIO}_{3}$ that dehydrates into $\mathrm{I}_{2} \mathrm{O}_{5}$ (eqn (6b)) and the amount of $\mathrm{HIO}_{3}$ that forms $\mathrm{HI}_{3} \mathrm{O}_{8}$ during heating (eqn (6a)) is shown in eqn (6).

$$
X_{\mathrm{HIO}_{3} \rightarrow \mathrm{HI}_{3} \mathrm{O}_{8}}=X_{\mathrm{HI}_{3} \mathrm{O}_{8}}-X_{\mathrm{HI}_{3} \mathrm{O}_{8}, \text { initial }}=\frac{\mathrm{ML} \% \mathrm{HI}_{3} \mathrm{O}_{8}}{1.76 \%}-X_{\mathrm{HI}_{3} \mathrm{O}_{8}, \text { initial }}
$$

$$
X_{\mathrm{HIO}_{3} \rightarrow \mathrm{I}_{2} \mathrm{O}_{5}}=X_{\mathrm{HIO}_{3}}-X_{\mathrm{HI}_{3} \mathrm{O}_{8}}
$$

In eqn (6), $\mathrm{ML}_{\mathrm{HI}_{3} \mathrm{O}_{8}}$ is the measured mass loss from TG analysis for $\mathrm{HI}_{3} \mathrm{O}_{8}, X_{\mathrm{HIO}_{3} \rightarrow \mathrm{I}_{2} \mathrm{O}_{5}}$ is the concentration of $\mathrm{HIO}_{3}$ that dehydrates directly into $\mathrm{I}_{2} \mathrm{O}_{5}, X_{\mathrm{HI}_{3} \mathrm{O}_{8}}$ is the concentration of $\mathrm{HI}_{3} \mathrm{O}_{8}$ used in eqn (3b) and is also the concentration of $\mathrm{HIO}_{3}$ that forms $\mathrm{HI}_{3} \mathrm{O}_{8}$ during heating $\left(\mathrm{X}_{\mathrm{HIO}_{3} \rightarrow \mathrm{HI}_{3} \mathrm{O}_{8}}\right)$ using eqn (4) assuming the initial concentration of $\mathrm{HI}_{3} \mathrm{O}_{8}$ is $0 \%$. The mechanism in eqn (4) is proposed because the accepted mechanism (eqn (1)) is a special condition but eqn (7) shows the conditions where the mechanism in eqn (4) is equivalent to the mechanism in eqn (1).

$$
\begin{gathered}
X_{\mathrm{HIO}_{3} \rightarrow \mathrm{HI}_{3} \mathrm{O}_{8}}=X_{\mathrm{HIO}_{3}} \\
X_{\mathrm{HIO}_{3} \rightarrow \mathrm{I}_{2} \mathrm{O}_{5}}=0
\end{gathered}
$$

The concentrations of $\mathrm{HIO}_{3}$ and $\mathrm{HI}_{3} \mathrm{O}_{8}$ calculated using the mechanism in eqn (1) and (4) are shown in ESI Tables S1 and S2. $\dagger$ The samples for which eqn (1) is not valid, because the concentration of $\mathrm{HIO}_{3}$ is greater than $100 \%\left(X_{\mathrm{HIO}_{3}}>100 \%\right)$, are shaded in ESI Tables S1 and S2. $\dagger$ The mechanism in eqn (4a) and (4b) may not have been observed by others because the methods previously used to study hydration of $\mathrm{I}_{2} \mathrm{O}_{5}$ are similar and thus produce similar results $\mathbf{1}^{\mathbf{1 , 4 , 8 , 1 1 , 1 2}}$ that follow eqn (1) and (7) where $\mathrm{HIO}_{3}$ dehydrates directly into $\mathrm{HI}_{3} \mathrm{O}_{8}$. The variables that determine whether the conditions in eqn (7) are met are not known. Multiple different experimental conditions (DSC heating rate, water impurities, hydration method (e.g., atmospheric $v$ s. dissolution in water), particle size, $\mathrm{I}_{2} \mathrm{O}_{5}$ synthesis method (e.g., dry or dehydration of $\mathrm{HIO}_{3}$ )) have been tested in an effort to determine the condition when eqn (1) is valid; however, a direct relation has not been found.

In previous studies, ${ }^{1,2}$ concentration of iodic acid has been verified by XRD analysis. The mechanism in eqn (4a) and (4b) does not affect the validity of these results and the XRD analysis from previous studies show that TGA is an accurate technique for determination of iodic acids. The XRD analysis happens over 1-2 hours for accurate measurements and $\mathrm{RH}$ cannot be controlled during measurements. For this study, the samples exposure to $20 \% \mathrm{RH}$ was limited to less than 5 minutes. The limitation on exposure time in $20 \% \mathrm{RH}$ and the time needed for XRD analysis did not allow XRD data collection.

\section{Assumptions}

The model described in eqn (4)-(7) is based on assumptions that may not have been considered previously. We have shown that the accepted mechanism for dehydration of iodic acids is a special condition that is violated when the ratio of mass loss from $\mathrm{HIO}_{3}$ to $\mathrm{HI}_{3} \mathrm{O}_{8}$ is greater than 1.9 or when the mass loss of water from $\mathrm{HIO}_{3}$ is greater than $3.14 \%$. These are general conditions and are only valid when the only mass loss is water from dehydration of $\mathrm{HIO}_{3}$ (not residual water). When $\mathrm{I}_{2} \mathrm{O}_{5}$ is hydrated by exposure to $80 \% \mathrm{RH}$, this assumption does not always hold and is seen by a total mass loss greater than $5.11 \%$. Samples that have a greater mass loss then $5.11 \%$ are assumed to have residual water and are underlined in ESI Tables $\mathrm{S} 1$ and S2. $\dagger$ For accurate calculation of initial $\mathrm{HIO}_{3}$ and $\mathrm{I}_{2} \mathrm{O}_{5}$ concentration, it is assumed that if total mass loss is greater than $5.11 \%$, the sample is initially pure $\mathrm{HIO}_{3}$. The validity of the assumption that residual water in the sample indicates the sample is pure $\mathrm{HIO}_{3}$ is discussed below. The calculated concentrations for each sample using eqn (3) and the assumption that the concentration of $\mathrm{HIO}_{3}$ is $100 \%$ for samples with a greater total mass loss than $5.11 \%$ is shown in Tables 3 and 4 .

In Tables 3 and 4, the concentration of $\mathrm{HIO}_{3}$ that dehydrates into $\mathrm{I}_{2} \mathrm{O}_{5}$ is negative for the $17 \mu \mathrm{m}$ sample after an exposure time 
Table 3 Composition of $17 \mu \mathrm{m} \mathrm{I}_{2} \mathrm{O}_{5}$ calculated using eqn (5) and (6). Values are calculated assuming $\mathrm{X}_{\mathrm{HI}_{3} \mathrm{O}_{8} \text {,initial }}=0$ and that mass loss over $5.11 \%$ indicates the sample is $100 \% \mathrm{HIO}_{3}$

\begin{tabular}{llllll}
\hline $\begin{array}{l}\text { Exposure time } \\
(\mathrm{min})\end{array}$ & $\begin{array}{l}\text { Residual water } \\
(\mathrm{g})\end{array}$ & $X_{\mathrm{HIO}_{3}}$ & $X_{\mathrm{H}_{3} \mathrm{O}_{8}}$ & $X_{\mathrm{I}_{2} \mathrm{O}_{5}}$ & $X_{\mathrm{HIO}_{3} \rightarrow \mathrm{I}_{2} \mathrm{O}_{5}}$ \\
\hline 1 & 0 & $0.4 \%$ & $1.1 \%$ & $99.6 \%$ & $-0.7 \%$ \\
5 & 0 & $1.6 \%$ & $4.5 \%$ & $98.4 \%$ & $-3.0 \%$ \\
10 & 0 & $1.2 \%$ & $3.4 \%$ & $98.8 \%$ & $-2.2 \%$ \\
15 & 0 & $36.4 \%$ & $13.0 \%$ & $63.6 \%$ & $23.3 \%$ \\
30 & 0 & $54.8 \%$ & $5.7 \%$ & $45.2 \%$ & $49.1 \%$ \\
180 & 0.47 & $100.0 \%$ & $12.5 \%$ & $0.0 \%$ & $87.5 \%$ \\
900 & 0.24 & $100.0 \%$ & $9.6 \%$ & $0.0 \%$ & $90.4 \%$ \\
2680 & 0.36 & $100.0 \%$ & $16.4 \%$ & $0.0 \%$ & $83.6 \%$ \\
& & & & &
\end{tabular}

Table 4 Composition of $5 \mu \mathrm{m} \mathrm{I}_{2} \mathrm{O}_{5}$ calculated using eqn (5) and (6).

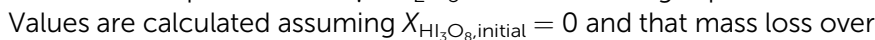
$5.11 \%$ indicates the sample is $100 \% \mathrm{HIO}_{3}$

\begin{tabular}{llllll}
\hline $\begin{array}{l}\text { Exposure time } \\
(\mathrm{min})\end{array}$ & $\begin{array}{l}\text { Residual water } \\
(\mathrm{g})\end{array}$ & $X_{\mathrm{HIO}_{3}}$ & $X_{\mathrm{HI}_{3} \mathrm{O}_{8}}$ & $X_{\mathrm{I}_{2} \mathrm{O}_{5}}$ & $X_{\mathrm{HIO}_{3} \rightarrow \mathrm{I}_{2} \mathrm{O}_{5}}$ \\
\hline 1 & 0 & $30.1 \%$ & $23.8 \%$ & $69.9 \%$ & $6.3 \%$ \\
5 & 0 & $50.5 \%$ & $32.3 \%$ & $49.5 \%$ & $18.2 \%$ \\
10 & 0 & $96.2 \%$ & $16.4 \%$ & $3.8 \%$ & $79.8 \%$ \\
30 & 0 & $99.0 \%$ & $18.1 \%$ & $1.0 \%$ & $80.8 \%$ \\
85 & 0 & $98.8 \%$ & $28.3 \%$ & $1.2 \%$ & $70.4 \%$ \\
220 & 0.019 & $100.0 \%$ & $27.8 \%$ & $0.0 \%$ & $72.2 \%$ \\
2880 & 0.018 & $100.0 \%$ & $23.8 \%$ & $0.0 \%$ & $76.2 \%$
\end{tabular}

of 1,5 and 10 minutes (underlined). The negative value for the concentration of $\mathrm{HIO}_{3}$ that dehydrates into $\mathrm{I}_{2} \mathrm{O}_{5}$ is a result of the assumption that the initial concentration of $\mathrm{HI}_{3} \mathrm{O}_{8}$ is $0.0 \%$. The new mechanism (i.e., eqn (4)) has an inherent assumption that during hydration, $\mathrm{I}_{2} \mathrm{O}_{5}$ hydrates directly into $\mathrm{HIO}_{3}$. Any $\mathrm{I}_{2} \mathrm{O}_{5}$ that hydrates directly into $\mathrm{HI}_{3} \mathrm{O}_{8}$ will show up as initial $\mathrm{HI}_{3} \mathrm{O}_{8}$ in the model shown in eqn (4)-(7) because it is not possible to differentiate between $\mathrm{HI}_{3} \mathrm{O}_{8}$ that is formed during heating and $\mathrm{HI}_{3} \mathrm{O}_{8}$ that is formed during hydration. This leads to the small error $(<1.6 \%)$ in $\mathrm{HIO}_{3}$ concentration calculated using eqn (5a). Since $\mathrm{HI}_{3} \mathrm{O}_{8}$ is an adjunct of $\mathrm{HIO}_{3}$ and $\mathrm{I}_{2} \mathrm{O}_{5},{ }^{13}$ the small error in $\mathrm{HIO}_{3}$ calculated using total mass in eqn (5a) is the amount of $\mathrm{HIO}_{3}$ in $\mathrm{HI}_{3} \mathrm{O}_{8}$ from hydration. The model in eqn (4)-(7) can be improved by determining the amount of $\mathrm{HI}_{3} \mathrm{O}_{8}$ formed during hydration, but a method to determine the amount of $\mathrm{HI}_{3} \mathrm{O}_{8}$ formed during hydration has not been developed. Examining the absorption behavior of these samples can help verify the validity of the assumptions that initial concentration of $\mathrm{HI}_{3} \mathrm{O}_{8}$ is $0.0 \%$ and that mass loss over $5.11 \%$ indicates the samples in $100 \% \mathrm{HIO}_{3}$. By weighing samples before and after exposure to $80 \% \mathrm{RH}$, differences in absorption and hydration were measured.

\section{$\mathrm{HI}_{3} \mathrm{O}_{8}$ formation from hydration}

Tables 1 and 2 show the mass gain from absorption in $80 \% \mathrm{RH}$ and the mass loss from $\mathrm{HIO}_{3}$ dehydration. In both samples, the mass gained from absorption is higher than the total iodic acid mass loss from dehydration. After exposure to $80 \% \mathrm{RH}$ in a humidity chamber, the samples were removed from the camber and exposed to $20 \% \mathrm{RH}$ ambient environment for weighing and placement in the STA. Since only the RH of the environment is changed after the samples are removed from the humidity chamber, the difference between mass gain and mass loss is assumed to be caused by rapid desorption of residual water and/ or $\mathrm{IO}_{3}{ }^{-}$solution. The time of exposure to low humidity was kept as constant as possible and was less than 30 seconds for weight measurements and less than 5 minutes for DSC loading. This limitation to the experimental setup inadvertently helps explain the differences between absorption and the hydration mechanism. The difference in mass gain from absorption and mass loss from dehydration of $\mathrm{HIO}_{3}$ indicates that hydration of $\mathrm{I}_{2} \mathrm{O}_{5}$ into $\mathrm{HIO}_{3}$ is a time dependent reaction. The time dependence of this reaction could influence the hydration mechanism and allow $\mathrm{HI}_{3} \mathrm{O}_{8}$ to form during hydration.

In Table 1 for $17 \mu \mathrm{m} \mathrm{I}_{2} \mathrm{O}_{5}$, there is no mass loss from dehydration of $\mathrm{HIO}_{3}$ until 15 minutes exposure time, but a mass gain of $1.0 \%, 1.5 \%$, and $3.2 \%$, and a total mass loss of $0.02 \%, 0.08 \%$, and $0.06 \%$ is seen at 1,5 , and 10 minutes exposure time, respectively. The results in Table 1 indicate the mass loss is due to dehydration of $\mathrm{HI}_{3} \mathrm{O}_{8}$, indicating that initially, $\mathrm{HI}_{3} \mathrm{O}_{8}$ is forming instead of $\mathrm{HIO}_{3}$ for the $17 \mu \mathrm{m} \mathrm{I}_{2} \mathrm{O}_{5}$. Fig. 3c shows that mass gain in the first 30 minutes of exposure time for both 17 $\mu \mathrm{m} \mathrm{I}_{2} \mathrm{O}_{5}$ and $5 \mu \mathrm{m} \mathrm{I}_{2} \mathrm{O}_{5}$. The $17 \mu \mathrm{m} \mathrm{I}_{2} \mathrm{O}_{5}$ initially has a fast rate of absorption with an inflection point at 10 minutes where the absorption rate decreases (Fig. 3c). After 10 minutes exposure time, mass loss in the $\mathrm{HIO}_{3}$ dehydration temperature range is seen. The inflection point at 10 minutes and mass loss in the $\mathrm{HIO}_{3}$ dehydration temperature range after 10 minutes exposure suggests that the increased rate of absorption in the $17 \mu \mathrm{m} \mathrm{I}_{2} \mathrm{O}_{5}$ is due to $\mathrm{I}_{2} \mathrm{O}_{5}$ forming directly into $\mathrm{HI}_{3} \mathrm{O}_{8}$, and after the rate of absorption slows, water that is absorbed starts to hydrate $\mathrm{I}_{2} \mathrm{O}_{5}$ into $\mathrm{HIO}_{3}$. The $5 \mu \mathrm{m} \mathrm{I}_{2} \mathrm{O}_{5}$ does not have an inflection point where the rate of absorption slows and does not have exposure times where mass loss from $\mathrm{HI}_{3} \mathrm{O}_{8}$ and no mass loss from $\mathrm{HIO}_{3}$ is seen. We speculate that the differences in absorption behavior and formation of $\mathrm{HI}_{3} \mathrm{O}_{8}$ are a result of the different particle size or processing methods. Decreased specific surface area of $17 \mu \mathrm{m}$ $\mathrm{I}_{2} \mathrm{O}_{5}$ could slow absorption. If hydration of $\mathrm{I}_{2} \mathrm{O}_{5}$ into $\mathrm{HIO}_{3}$ is dependent on absorption rate, the slower absorption rate of 17 $\mu \mathrm{m} \mathrm{I}_{2} \mathrm{O}_{5}$ could slow the hydration rate of $\mathrm{I}_{2} \mathrm{O}_{5}$ into $\mathrm{HIO}_{3}$. $\mathrm{HI}_{3} \mathrm{O}_{8}$ is an adjunct of $\mathrm{HIO}_{3}$ and $\mathrm{I}_{2} \mathrm{O}_{5}$ and $\mathrm{HIO}_{3}$ and $\mathrm{I}_{2} \mathrm{O}_{5}$ must both be present to form $\mathrm{HI}_{3} \mathrm{O}_{8}$. If the absorption rate of $17 \mu \mathrm{m} \mathrm{I}_{2} \mathrm{O}_{5}$ slows the hydration rate of $\mathrm{I}_{2} \mathrm{O}_{5}$ to the point where both $\mathrm{I}_{2} \mathrm{O}_{5}$ and $\mathrm{HIO}_{3}$ are present, then formation of $\mathrm{HI}_{3} \mathrm{O}_{8}$ could be a result of particle size. Alternatively, the processing method between $17 \mu \mathrm{m} \mathrm{I}_{2} \mathrm{O}_{5}$ and $5 \mu \mathrm{m} \mathrm{I}_{2} \mathrm{O}_{5}$ could result in conditions where the formation of $\mathrm{HI}_{3} \mathrm{O}_{8}$ is favored over the formation of $\mathrm{HIO}_{3}$ in $17 \mu \mathrm{m} \mathrm{I}_{2} \mathrm{O}_{5}$, and the difference in absorption is a result of formation of $\mathrm{HI}_{3} \mathrm{O}_{8}$. The $17 \mu \mathrm{m} \mathrm{I}_{2} \mathrm{O}_{5}$ were created by dehydration of commercial $\mathrm{I}_{2} \mathrm{O}_{5}$ that has been shown to be composed mostly of $\mathrm{HI}_{3} \mathrm{O}_{8}{ }^{2,7,10}$ The dehydration of $\mathrm{HI}_{3} \mathrm{O}_{8}$ during the heating process could leave discontinuities in the crystal lattice that could favor the formation of $\mathrm{HI}_{3} \mathrm{O}_{8}$ over $\mathrm{HIO}_{3}$ during hydration. The initial formation of $\mathrm{HI}_{3} \mathrm{O}_{8}$ may not be seen in the $5 \mu \mathrm{m} \mathrm{I}_{2} \mathrm{O}_{5}$ because it is created using a "dry" method and may have more limited discontinuities 
in the crystal lattice formed from initial dehydration. $\mathrm{HI}_{3} \mathrm{O}_{8}$ that is formed during hydration cannot be distinguished from $\mathrm{HI}_{3} \mathrm{O}_{8}$ that is formed during heating and leads to the error shown in Tables 3 and 4 . Because of this, further studies are need to determine the effects of particle size and processing methods on absorption and formation of $\mathrm{HI}_{3} \mathrm{O}_{8}$.

\section{Residual water}

The other major assumption used in the calculation of iodic acid concentration from TGA is that any mass loss over $5.11 \%$ indicates that the sample is entirely composed of $\mathrm{HIO}_{3}$. In both 17 $\mu \mathrm{m} \mathrm{I}_{2} \mathrm{O}_{5}$ and $5 \mu \mathrm{m} \mathrm{I}_{2} \mathrm{O}_{5}$, more water is absorbed than is needed to hydrate $\mathrm{I}_{2} \mathrm{O}_{5}$ into $\mathrm{HIO}_{3}$. The maximum mass gained for $5 \mu \mathrm{m} \mathrm{I}_{2} \mathrm{O}_{5}$ is $9.1 \%$ at an exposure time of 30 minutes and the maximum mass gain for the $17 \mu \mathrm{m} \mathrm{I}_{2} \mathrm{O}_{5}$ is $34.8 \%$ at an exposure time of 180 minutes. Also, the first exposure time where the mass loss is over $5 \%$ for $5 \mu \mathrm{m} \mathrm{I}_{2} \mathrm{O}_{5}$ is at an exposure time of 30 minutes and the first exposure time where the mass loss is over $5 \%$ for $17 \mu \mathrm{m} \mathrm{I}_{2} \mathrm{O}_{5}$ is at an exposure time of 180 minutes. The exposure time where maximum mass gain is seen and mass loss first reaches $5 \%$ suggests that at these exposure times, all $\mathrm{I}_{2} \mathrm{O}_{5}$ has reacted with water to form $\mathrm{HIO}_{3}$. Residual water is shown in Tables 3 and 4 and there is no residual water until after the exposure times where maximum mass gain is seen and mass loss first reaches $5 \%$. This suggests that residual water is not formed until all $\mathrm{I}_{2} \mathrm{O}_{5}$ has reacted with water to form $\mathrm{HIO}_{3}$ and the assumption that mass loss over $5.11 \%$ indicates the sample is pure $\mathrm{HIO}_{3}$ is reasonable. Fig. $3 \mathrm{a}$ and $\mathrm{b}$ also show that the mass gained starts to decrease after all $\mathrm{I}_{2} \mathrm{O}_{5}$ has reacted to form $\mathrm{HIO}_{3}$. We propose that maximum mass gain is related to the particle size and the extra water reacts with $\mathrm{I}_{2} \mathrm{O}_{5}$ to form an $\mathrm{IO}_{3}{ }^{-}$solution. When the samples are removed from $80 \% \mathrm{RH}$ to $20 \% \mathrm{RH}$ for weighing and loading into the DSC, rapid desorption of extra water occurs forming an $\mathrm{HIO}_{3}$ crystal structure. The decrease in mass gain after 180 minutes exposure for $17 \mu \mathrm{m} \mathrm{I}_{2} \mathrm{O}_{5}$ and 30 minutes for 5 $\mu \mathrm{m} \mathrm{I}_{2} \mathrm{O}_{5}$ indicates that an $\mathrm{HIO}_{3}$ crystal structure is forming while still exposed to $80 \% \mathrm{RH}$. The $\mathrm{HIO}_{3}$ crystal structure that is formed while the samples are still exposed to $80 \% \mathrm{RH}$ acts as a diffusion barrier that slows the rapid desorption of water when the samples are taken from $80 \% \mathrm{RH}$ to $20 \% \mathrm{RH}$. The diffusion barrier traps the extra water/ $\mathrm{IO}_{3}{ }^{-}$solution in the sample. When the samples are heated in the DSC, discontinuities in the crystal structure are formed by dehydration of the $\mathrm{HIO}_{3}$, reducing the effects of the diffusion barrier and allowing the residual water to be released in the dehydration temperature range of $\mathrm{HIO}_{3}$. Further studies with a greater range of particle sizes and synthesis methods will allow us to determine the effects that these variables have on the formation of $\mathrm{HI}_{3} \mathrm{O}_{8}$ and residual water. A better understanding of these variables could eliminate the need for the assumptions that introduce error, but are necessary to calculate concentration of iodic acid by TG mass change and eqn (4)-(7).

\section{Conclusion}

We have shown that the accepted dehydration mechanism is a special condition of a more general mechanism presented here. The condition where the accepted dehydration mechanism is equivalent to the new mechanism is when all $\mathrm{HIO}_{3}$ dehydrates directly into $\mathrm{HI}_{3} \mathrm{O}_{8}$. The new dehydration mechanism for $\mathrm{I}_{2} \mathrm{O}_{5}$ was proven by detecting reduced concentrations of $\mathrm{HI}_{3} \mathrm{O}_{8}$ in two different $\mathrm{I}_{2} \mathrm{O}_{5}$ powder samples. When $\mathrm{HIO}_{3}$ partially dehydrates directly into $\mathrm{I}_{2} \mathrm{O}_{5}$, the previously accepted mechanism breaks down because the concentration of $\mathrm{HIO}_{3}$ calculated is greater than $100 \%$. The model presented here more accurately predicts concentrations of iodic acids when assumptions about $\mathrm{HI}_{3} \mathrm{O}_{8}$ formation from hydration and residual water are made. The validity of the assumptions is shown by comparisons of mass gained during hydration and mass lost during heating. The data presented confirms the validity of the assumptions, but also show that these assumptions introduce small error in the iodic acid concentrations calculated. Further studies are needed that would allow us to expand the hydration/dehydration model that would allow the concentration of iodic acid to be calculated without assumptions that lead to error.

\section{Acknowledgements}

The authors Smith and Pantoya are grateful for partial support from DTRA under award HDTRA1-15-1-0029. The authors Parkey and Kesmez are grateful for support from DTRA under award HDTRA1-15-P-0037. We are all grateful for helpful discussion and encouragement from our program manager, Dr Douglas Allen Dalton.

\section{References}

1 K. Selte and A. Kjekshus, Iodine Oxides Part II on the System $\mathrm{H}_{2} \mathrm{O} \mathrm{I}_{2} \mathrm{O}_{5}$, Acta Chem. Scand., 1968, 22, 3309-3320.

2 B. K. Little, S. B. Emery, J. C. Nittinger, R. C. Fantasia and C. M. Lindsay, Physiochemical Characterization of Iodine(v) Oxide, Part 1: Hydration Rates, Propellants, Explos., Pyrotech., 2015, 40, 595-603.

3 M. W. Chase, NIST-JANAF Thermochemical Tables for the Iodine Oxides, J. Phys. Chem. Ref. Data, 1996, 25(5), 12971340 .

4 R. Kumar, R. W. Saunders, a. S. Mahajan, J. M. C. Plane and B. J. Murray, Physical Properties of Iodate Solutions and the Deliquescence of Crystalline $\mathrm{I}_{2} \mathrm{O}_{5}$ and $\mathrm{HIO}_{3}$, Atmos. Chem. Phys., 2010, 10(24), 12251-12260.

5 J. Feng, G. Jian, Q. Liu and M. R. Zachariah, Passivated Iodine Pentoxide Oxidizer for Potential Biocidal Nanoenergetic Applications, ACS Appl. Mater. Interfaces, 2013, 5(18), 8875-8880.

6 A. B. Lamb, W. C. Bray and W. J. Geldard, The Preparation of Iodic Acid and Its Anhydride, J. Am. Chem. Soc., 1920, 42(8), 1636-1648.

7 D. K. Smith, K. Hill, M. L. Pantoya, J. S. Parkey and M. Kesmez, Reactive Characterization of Anhydrous Iodine(v) Oxide $\left(\mathrm{I}_{2} \mathrm{O}_{5}\right)$ with Aluminum: Amorphous versus Crystalline Microstructures, Thermochim. Acta, 2016, 641, 55-62. 
8 K. Selte and A. Kjekshus, Iodine Oxides Part III. The Crystal Structure of $\mathrm{I}_{2} \mathrm{O}_{5}$, Acta Chem. Scand., 1970, 6(24), 1913-1924.

9 A. Wikjord, P. Taylor, D. Torgerson and L. Hachkowski, Thermal Behaviour of Corona-Precipitated Iodine Oxides, Thermochim. Acta, 1980, 36(3), 367-375.

10 D. K. Smith, J. McCollum and M. L. Pantoya, Effect of Environment of Iodine Oxidation State on Reactivity with Aluminum, Phys. Chem. Chem. Phys., 2016, 18, 11243-11250. 11 B. K. Little, E. J. Welle, S. B. Emery, M. B. Bogle, V. L. Ashley, A. M. Schrand and C. M. Lindsay, Chemical Dynamics of
Nano-Aluminum/iodine(v) Oxide, J. Phys.: Conf. Ser., 2014, 500(5), 52025.

12 B. Little, S. Emery and C. Lindsay, Physiochemical Characterization of Iodine(v) Oxide Part II: Morphology and Crystal Structure of Particulate Films, Crystals, 2015, 5(4), 534-550.

13 A. Fischer, Redetermination of $\mathrm{HI}_{3} \mathrm{O}_{8}$, an Adduct of $\mathrm{HIO}_{3}$ $\mathrm{I}_{2} \mathrm{O}_{5}$, Acta Crystallogr., Sect. E: Struct. Rep. Online, 2005, 61, 278-279. 